\title{
Personal Vaporizer
}

National Cancer Institute

\section{Source}

National Cancer Institute. Personal Vaporizer. NCI Thesaurus. Code C120481.

A battery-powered atomizer designed to aerosolize a liquid solution for inhalation. 